\title{
Risk factors, clinical outcome and complications of Common Gynecological Surgeries at Zagazig University Hospital, Egypt
}

Safaa A. Ibrahim

Zagazig University Faculty of Human Medicine

Mena M. Abdalla ( $\nabla$ dr.menasaleeb@yahoo.com )

Minya Health Insurance Hospital https://orcid.org/0000-0002-6395-0391

\section{Original Article}

Keywords: gynecological surgeries, risk factors, complications, mortality

Posted Date: February 3rd, 2021

DOI: https://doi.org/10.21203/rs.3.rs-170186/v1

License: (c) (1) This work is licensed under a Creative Commons Attribution 4.0 International License.

Read Full License 


\section{Abstract}

In present era, with the availability of better health care facilities and understanding of health issues, women are experiencing longer life expectancy and using more gynecological services, so obviously there is increase in gynecological surgeries. Any surgical procedure carries risks of complications. The risk of postoperative complications depends on individual characteristics, including age, medical comorbidities, and functional status. The aim of study was to reduce rates of mortality/morbidity among women who undergo surgical gynecological intervention at Zagazig University Hospital. This study included 212 cases were retrived prospectively in a cross sectional study. They underwent gynecological interventions. Our study group was 212 cases 24 cases ended with morbidity with percentage of $11.3 \%$ and 2 cases ended by death with percentage of $0.9 \%$. This study shows that the most frequent complications among the studied group were septic wound infection (2.4\%), bladder injury $(2.4 \%)$, respiratory tract infection (1.9\%),Venous thromboembolism(VTE) (1.9\%) and GIT injury (1.4\%). This study explains that there were two mortality cases the first case died on table due to primary hemorrhage during hysterectomy operation as a result of great vessel injury and the other case died during hysterectomy operation due to venous thromboembolic catastrophe (Pulmonary embolism). During post-operative period, she developed hypoxia; therefore, she was referred to ICU. Unfortunately, the patient was diagnosed as pulmonary embolism; thus, she was admitted at ICU for 3 days, but she finally died.

Conclusion With the availability of highly skilled personnel with improved surgical expertise, safe anesthesia and collaboration of other specialized medical personnel, the major complications and mortality rate will decrease, but the postoperative complications like, fever, respiratory tract infection, septic wound and DVT still frequent in a significant number of patients in our community, which brings about much distress to the patients.

\section{Introduction}

At present, with better health facilities and an understanding of health issues, women have longer lives expectancy and are using more gyneecological services, so it goes without saying that gynaecological operations are increasing (1).

Any operation carries the risk of complications. The risk of postoperative complications depends on the characteristics of age, medical comorbidity and function (2).

It is important that potential known risk factors are identified in the examination of patients for surgical operations and this should be part of good clinical practise. Any complication, for example the presence of intra-abdominal adhesion, visceral injuries and postoperative infections, should be discussed with prior abdominal surgeries, including indication and route. Conditions that make operations complicated, including endometriosis, cancer, disturbed coagulation and obesity should also be noted as these increase the chances of injury (3). 
During gynaecological operation, complications result from the proximity of the uterus and ovaries to other critical pelvic structures. These include the urinary tract, intestine, nerves and blood vessels. In performing these procedures, knowledge of pelvic anatomy is essential and critical for altered anatomy due to adhesive disease and during intraoperative haemorrhage. Unintended injury recognition and repair offers the best possibility to minimise sequelae of these complications (4).

For safe surgery, high-risk areas should be identified and the way to minimise them. Every surgeon may experience complications at some point but it is necessary to detect when these occur and the most suitable initial management to prevent or minimise immediate and long-term complications. Injury should be detected during surgery; the steps necessary to repair the injury will prolong the anaesthetic and recovery of the patient. We therefore decide to investigate the complications of major gynaecological operations (5).

\section{Aim of the work}

To reduce rates of mortality/morbidity among women who undergo surgical gynecological intervention at Zagazig University Hospital.

\section{Patients And Methods}

To reduce rates of mortality/morbidity among women who undergo surgical gynecological intervention at Zagazig University Hospital.

\section{Patients and Methods}

This cross-sectional observational study was conducted at the Department of Obstetrics and Gynecology at Zagazig University Hospital from January 2019 to January 2020.

\section{Patients:}

The sample size was calculated according to the total number of cases coming before to Zagazig University Hospital, for gynecological surgery in 1 year, which was 500 cases and the frequency of complications in gynecological surgery was $3.7 \%$. So at a power of study $80 \%$, and a $\mathrm{Cl} 95 \%$, the sample size was calculated to be 212 cases with no drops in patients.

\section{Sample Size Estimation: Cross Sectional (One Group) _Proportion}

- Formula:

$n=Z^{2}{ }_{1-} A_{12} P(1-P) / d^{2}$, where,

$\mathrm{n}=$ sample size 
$Z^{2}{ }_{1-} A_{12}=$ confidence interval

$\mathrm{P}=$ estimated proportion

$\mathrm{d}=$ desired precision

\section{Inclusion criteria:}

All females undergoing any gynecological surgical interventions as: hysterectomy (abdominal, vaginal, laparoscopic), procedures for prolapse, vaginal procedures.

\section{Exclusion criteria:}

- Women admitted for non-gynecological surgical intervention.

- Patients who deny consent.

\section{Methods:}

Confirmed that there were written informed consents obtained from patients if complications occur and see all information from patients' carts as:

1. Complete history taking.

2. Clinical and laboratory results.

3. Important intra-operative events such as :

- Level of surgeon.

- Type of surgery.

- Duration of surgery.

- Blood loss.

- Reporting of intra operative complications.

4. Postoperative follow up.

5. Reporting of post-operative complications.

6. The management of complications either conservatively or by surgical intervention.

All data was collected from the patients' follow up cards.

\section{Statistical analysis:}

- The collected data were computerized and statistically analyzed using SPSS program (Statistical Package for Social Science) version 18.0.

\section{Results}


This cross-sectional observational study was conducted at the Department of Obstetrics and Gynecology at Zagazig University Hospital from January 2019 to January 2020 included 212 patients. table 1 shows that age of the studied group ranged from 12 to 80 years old with mean 45.86 years old and $55.7 \%$ of them were 45 years old or more. Regarding parity 7 cases were virgin (3.3\%) and $10.4 \%$ nullipara, $4.2 \%$ had 1 child and $82.1 \%$ were multipara ranged from 2 to 10 children. Table 2 shows that $44.3 \%$ of surgery were simple hysterectomy, $10.8 \%$ were Wertheim operation or adenexectomy, $9.9 \%$ were classical repair and $5.7 \%$ were vaginal hysterectomy. Also most of surgeries were performed by Assistant prof \& Prof $(60.9 \%)$. table 3 shows that $88.7 \%$ of the studied group had no complication after surgery. the most frequent complications among the studied group were septic wound infection, bladder injury, respiratory tract infection, Venous thromboembolism(VTE) and GIT injury, $(2.4 \%, 2.4 \%, 1.9 \%, 1.9 \%$ and $1.4 \%$ respectively).Table 4 shows that the most prevalent medical disorder in complicated and noncomplicated group is diabetes $37.5 \%$ and $10.6 \%$ respectively followed by hypertension $25 \%$ and $9 \%$ respectively. Table 5 shows that mortality rate among the studied group was $0.9 \%$. One case died from primary hemorrhage and the second from pulmonary embolism. table 6 shows that there was no relation between complication and level of doctors but there was statistical significance increase in frequency of complication in old age group $\geq 45$ years, in female had children and in Wertheim operation cases. Table 7 show that there is significant difference between the previous laparotomy group and the no abdominal surgery group as regard complications. table 8 shows that there is significant difference between the two groups as regard venous thromboembolism. While there is no significant difference between the two studied groups as regard other complications.

\section{Discussion}

Every operation has complications and is one of the main elements of surgical practice. In order to avoid or minimize immediate and long-term complications, recognition of those complications and proper management is essential. Furthermore, because some complications involve areas where the surgeon has comparatively little expertise, it is important to recognize that limitation and assistance from a suitable specialist is very important to patients at an early stage. (6).

Factors that predispose to complications during or after surgery and pre-operative strategies for determining such factors with recommendations for reducing their incidence will be taken into account. (7).

Large gynaecological operations often involve meticulous dissection near the pelvis' bladder, rectum, ureters and large pelvic vessels. Hemorrhage, infection, thromboembolism and visceral damage are complications of gynaecological surgery. The risk of complications depends on the extent and approach of the operation and the patient's features. The more common complications of this surgery can understandably be associated with these viscera wounds and occur during extensive cancer treatment resections or when anatomy is distorted due to infection or endometriosis. (8). 
Pre-operative assessment should identify intraoperative or post-operative areas of concern. This information can be used by the surgeon to prepare the woman for operation and to plan for any preoperational measures necessary to avoid or manage complications. (9).

This study gave us an idea about the rate of morbidity and mortality following common surgical gynaecology and this study was never done at the University of Zagazig before. This is a cross-sectional observatory study on important intraoperative and postoperative surgical events such as surgery type, surgeon status, complication type and mortality. The main factors that lead to mortality are identified in 212 women.

This study showed that the age of the studied group varied from 12 to 80 years, with average $45.86 \pm$ 12.41 years. We found that $44.3 \%$ of the study group were under 45 years of age with $55.7 \%$ over the age of 45 years, and that the incidence of complications increased in patients with a significant $P$ value of more than 45 years (0.01). This is consistent with a study done by Erekson and his colleagues, which showed that complications have increased incidence of increasing patient age (10).

With regard to the relation between parity and the incidence of complications, the incidence of complications with increased parity is increasing, our results showed that multiparas have more than virgin complications, and that the results may be due to the increase in the number of multiparas women in the study than others.

This study shows that most patients were subject to simple hysterectomy with $44.3 \%$ of patients, $10.8 \%$ had Wertheim operation and similar\% also received adenexectomy, 9.9\% were classical repair and $5.7 \%$ were vaginal hysterectomy.

In order to report on overall complications following gynaecological surgery, we have decided to examine most of our gynaecological procedures (including laparotomies, vaginal procedure and procedure for gynaecological cancer). Both laparotomies and gynaecological cancer procedures were more complicated than vaginal treatments.

We have reported variable complications in this study (septic wound, bladder injury, respiratory tract infection, VTEs, GIT injury, primary haemorrhage in OR and pulmonary edema).

Wound infection is one of the most common postoperative complications in the case of septic wound and is responsible for significant morbidity. In our study there are only 5 cases in 212 patients with a percentage of septic injury (2.4 percent). According to the data published by (Dicker et al., 1982), the incidence of wound infection was $5 \%$ and current figures (Siddiqua et al., 2016) showed that the same low percentage of wound infected cases occurred. The current use of preoperative prophylactic antibiotics can be responsible for this low incidence of infection. $(11,12)$.

The sexual and urinary tracts of women are anatomically closely related, so the potential for injury to one person should always be taken into consideration when acting on the other. Urinary tract injury is one of the most common complications after gynaecological surgery. 
This study revealed that urinary tract injury was $2.4 \%$ among five cases, and the results of a retrospective study (Wallis et al., 2016) show 242 patients (2.4\%), with 1011021 patients having hysterectomy, urinary tract injury, and the urological intervention required (13)

Infection of the respiratory tract is a very common post-operative complication, which may be associated with anaesethia and poor post-operative ambulance, and prolonged hospital hospital stay associated with nosocomial chest infection. In our study 4 RTI cases with a percentage of 1.9 percent were developed. These results are consistent with a study by (Siddiqua et al., 2017) that showed three RTI cases from 100 cases with a percentage of $3 \%$. (12) .

As regards the development of postoperative DVT, 4 of the cases in our study (1.9 percent) developed postoperative DVT and the study agreed that five of 430 patients (1.2 percent) developed postoperative venous thromboembolism. (14).

This change in results is explained by our routine use of prophylactic anticoagulation which lowers the incidence of vein thromboembolism (15). On one hand, a further study (Sandadi et al. 2012) shows that the percentage of DVT occurred in the post-operative period is higher (9.5 percent).

Injury to the bowel is a potential complication of any abdominal or retroperitoneal surgery and is still a serious complication. In our study $3(1.4 \%)$ of 212 cases, GIT injury had a gynaecological complication. This result is consistent with data published by (Bishoff et al. 1999) which showed that GIT injury was $(0.8 \%)$ a complication of gynaecological operation in cases (16)

There were only two cases of primary haemorrhage in this study (0.9 percent). One of them required reexploration, the other case died on the table after massive blood loss.

Only one case (1\%) of 100 cases involved in the study (Siddiqua et al., 2017) showed postoperative haemorrhage.

On other complications there is only one case in which pulmonary edoema has developed and this is not a surgery complication (12).

In this study, 24 cases developed complications after surgery. We found 21 of them have chronic medical conditions during our analysis of these complicated cases, and 3 cases have been medically free.

Diabetes mellitus and hypertension were the most common medical conditions ( 9 cases $37.5 \%$ ) ( 6 cases 25 percent).

This study explained that most complicated cases were in simple hysterectomy groups with $50 \%$ of complicated patients. This is consistent with a study conducted on 135 retrospective cases by (McCracken et al., 2006) that showed a higher rate of abdominal hysterectomy complication (19.8\%) compared to the vaginal and laparoscopic groups (17). 
There are 212 patients in this study, only 24 of whom have intraoperative and postoperative complications ( 11.3 percent) developed, while only 2 mortality cases are in the study group (0.94 percent ) .

We found a similar frequency of major post-operational complications compared to others after gynaecological operations. In a 1991-1997 hysterectomy analysis at the Veterans Affairs Medical Centers (Weaver et al., 2001), the overall prevalence of all postoperative complications was reported to be (9.0\%). (18)

On the other hand, the overall mortality rate was $(0.06 \%)$ which is different from our $(0.94 \%)$ mortality rate. This difference can be related in comparison to this study to the limited number of cases in our study; no preoperative predictors were analysed in this study. Our results of 11.3 per cent lower composite morbidity are no surprise, because we excluded minor complications (urinary tract infections and surface injuries) and were concentrated on major postoperative events.

Obesity is usually regarded as a surgical risk factor but the risk level has been quantified inaccurately. There is little evidence that excess body weight alone should contraindicate general operation. Obesity is frequently associated with abnormal cardiorespiratory function, metabolism and haemostasis, which can predispose after surgery to morbidity and mortality. This study shows that the first case of death died on Table due to primary haemorrhage in hysterectomy, as mentioned above, was caused by a severe vessel injury; the first case died from venous thromboembolic disaster (pulmonary embolism); the second case, 78 , was previous medical history for diabetes mellitus, hypertension. She developed hypoxia during the post-operative period; therefore, she was referred to ICU. The patient was unfortunately diagnosed with lung embolism; she was therefore admitted to ICU for 3 days, but finally died.

\section{Conclusion}

With the availability of highly skilled personnel with improved surgical expertise, safe anesthesia and collaboration of other specialized medical personnel, the major complications and mortality rate will decrease, but the postoperative complications like, fever, respiratory tract infection, septic wound and DVT still frequent in a significant number of patients in our community, which brings about much distress of the patients.

The reasons behind it are:

- Low socioeconomic status.

- Poor knowledge about hygiene.

- People cannot afford costly antibiotics, and other necessary medications.

Again, hospital facilities were also at its minimum, too many patients needed to be accommodated in small place, many patients had to be operated in a same date, true post-operative isolation would not be possible and finally, visitor restriction in the post-operative ward also could not be strictly maintained. 


\section{References}

1 Gevariya, R., Oza, H., Doshi, H., \& Parikh, P. (2015). Epidemiology, Risk Factors and Outcome of Complications in Obstetric and Gynecological Surgeries-A Tertiary Center Experience from Western India. Journal of US-China Medical Science, 12, 45-52.

2 Henderson W and Daley J (2009): Design and statistical methodology of the national surgical quality improvement program: Why is it, what it is? The American Journal of Surgery; 198(5): S19.

3 Doshi, H., Gevariya, R., Oza, H., \& Parikh, P. (2015). Epidemiology, Risk Factors and Outcome of Complications in Obstetric and Gynecological Surgeries-A Tertiary Center Experience from Western India. Journal of US-China Medical Science, 12, 45-52.

4 Stany, M. P., \& Farley, J. H. (2008). Complications of gynecologic surgery. Surgical Clinics of North America, 88(2), 343-359.

5 Gopinath, D., \& Jha, S. (2016). Urological complications following gynaecological surgery. Obstetrics, Gynaecology \& Reproductive Medicine, 26(10), 291-296

6 Hodges, K. R., Davis, B. R., \& Swaim, L. S. (2014). Prevention and management of hysterectomy complications. Clinical obstetrics and gynecology, 57(1), 43-57.

7 Strik, C., Stommel, M. W., Schipper, L. J., van Goor, H., \& ten Broek, R. P. (2016). Risk factors for future repeat abdominal surgery. Langenbeck's archives of surgery, 401(6), 829-837.

8 Gopinath, D., \& Jha, S. (2016). Urological complications following gynaecological surgery. Obstetrics, Gynaecology \& Reproductive Medicine, 26(10), 291-296

9 Burnett, T. L., Junn, J., Kolenic, G. E., Christen, C., Johnston, C. M., Reynolds, R. K., \& McLean, K. (2016). Perioperative laboratory abnormalities in gynecologic oncology surgical patients. Journal of gynecologic surgery, 32(2), 111-118.

10 Erekson, E. A., Yip, S. O., Ciarleglio, M. M., \& Fried, T. R. (2011). Postoperative complications after gynecologic surgery. Obstetrics and gynecology, 118(4), 785.

11 Dicker, R. C., Scally, M. J. \& Greenspan, J. R. "Hysterectomy among women in reproductive age: Treands in United states, 1970-1978," JAMA, 1982, 248: 323-327.

12 Siddiqua, F., Moni, S. Y., Doty, N. B., \& Khanum, M. (2017). A study of Complications and Outcome of Major Gynaecological Operations-Analysis of 100 Cases. KYAMC Journal, 5(1), 444-448.

13 Wallis CJ, Cheung DC, Garbens A, et al. Occurrence of and Risk Factors for Urological Intervention During Benign Hysterectomy: Analysis of the National Surgical Quality Improvement Program Database. Urology 2016; 97:66. 
14 Nugent, E. K., Hoff, J. T., Gao, F., Massad, L. S., Case, A., Zighelboim, I., ... \& Thaker, P. H. (2011). Wound complications after gynecologic cancer surgery. Gynecologic oncology, 121(2), 347-352.

15 Sandadi S, Lee S, Walter A, et al. Incidence of venous thromboembolism after minimally invasive surgery in patients with newly diagnosed endometrial cancer. Obstet Gynecol. 2012; 120:1077-83.

[PubMed: 23090525]

16 Bishoff, J. T., Allaf, M. E., Kirkels, W. I. M., Moore, R. G., Kavoussi, L. R., \& Schroder, F. (1999). Laparoscopic bowel injury: incidence and clinical presentation. The Journal of urology, 161(3), 8

17 McCracken, G., Hunter, D., Morgan, D., \& Price, J. H. (2006). Comparison of laparoscopic-assisted vaginal hysterectomy, total abdominal hysterectomy and vaginal hysterectomy. The Ulster medical journal, 75(1), 54.

18 Weaver F, Hynes D, Goldberg JM, Khuri S, Daley J, Henderson W. Hysterectomy in veterans affairs medical centers. Obstet Gynecol. 2001; 97(6):880. [PubMed: 11384689] WJCC, 2(12), 846.

\section{Tables}

Table (1): Age and parity of the studied group:

\begin{tabular}{|c|c|c|}
\hline Variable & \multicolumn{2}{|c|}{$(\mathbf{n = 2 1 2 )}$} \\
\hline $\begin{array}{c}\text { Age : (year) } \\
\text { Mean } \pm S D \\
\text { Range }\end{array}$ & $\begin{array}{c}45.86 \pm 12.41 \\
12-80\end{array}$ \\
\hline $\begin{array}{c}\text { Parity } \\
\text { Mean } \pm S D \\
\text { Range }\end{array}$ & $\begin{array}{c}\text { 3.62 } \pm 2.09 \\
0-10\end{array}$ \\
\hline Variable & No & $\%$ \\
\hline Age group: & 94 & 44.3 \\
<45 years \\
$\geq 45$ years & 118 & 55.7 \\
\hline Parity: & 7 & 3.3 \\
Virgin & 72 & 10.4 \\
Nullipara & 22 \\
One & 9 & 4.2 \\
Multipara & 174 & 82.1 \\
\hline
\end{tabular}

Table (2): Type of surgery and level of doctor among the studied group: 


\begin{tabular}{|c|c|c|}
\hline Variable & \multicolumn{2}{|c|}{$(\mathbf{n = 2 1 2})$} \\
\cline { 2 - 3 } & No & $\%$ \\
\hline Type of surgery: & & \\
Simple hysterectomy & 94 & 44.3 \\
Wertheim operation & 23 & 10.8 \\
Adenexectomy & 23 & 10.8 \\
Classical repair & 21 & 9.9 \\
Myomectomy & 19 & 9 \\
Vaginal hysterectomy & 12 & 5.7 \\
Ovarian drilling & 11 & 5.2 \\
Repair of old perenial tear & 3 & 1.4 \\
Hymenotomy & 2 & 0.9 \\
Vault prolapse & 2 & 0.9 \\
TOT & 2 & 0.9 \\
\hline Doctor: & 27 & 12.7 \\
Assistant lecture & 56 & 26.4 \\
Lecture & 129 & 60.9 \\
\hline Assistant Prof or Prof
\end{tabular}

Table (3): Frequency and type of complication among the studied group:

\begin{tabular}{|c|c|c|}
\hline \multirow{2}{*}{ Variable } & \multicolumn{2}{|c|}{$(\mathbf{n = 2 1 2})$} \\
\cline { 2 - 3 } & No & $\%$ \\
\hline Complication: & & \\
No & 188 & 88.7 \\
Yes & 24 & 11.3 \\
\hline \multirow{2}{*}{ Variable } & \multicolumn{2}{|c|}{$(\mathbf{n}=212)$} \\
\cline { 2 - 3 } & No & $\%$ \\
\hline Septic wound infection & 5 & 2.4 \\
Bladder injury & 5 & 2.4 \\
Respiratory tract infection & 4 & 1.9 \\
Venous Thromboembolism (VTE) & 4 & 1.9 \\
GIT injury & 3 & 1.4 \\
Primary hemorrhage in OR & 2 & 0.9 \\
Pulmonary edema & 1 & 0.5 \\
\hline
\end{tabular}

Table (4): Medical disorders of the studied group: 


\begin{tabular}{|c|c|c|c|c|}
\hline \multirow{2}{*}{ Variable } & \multicolumn{2}{|c|}{$\begin{array}{c}\text { Complicated } \\
(\mathbf{n = 2 4 )}\end{array}$} & $\begin{array}{c}\text { Non Complicated } \\
\text { (n=188) }\end{array}$ \\
\cline { 2 - 5 } & No & \% & No & $\%$ \\
\hline Diabetes Mellitus & 9 & 37.5 & 20 & 10.6 \\
\hline Hypertension & 6 & 25 & 17 & 9 \\
\hline Cardiac & 2 & 8.3 & 9 & 4.7 \\
\hline Thyroid & 1 & 4.1 & 3 & 1.6 \\
\hline Hepatic & 2 & 8.3 & 12 & 6.3 \\
\hline Renal & 1 & 4.1 & 6 & 3.2 \\
\hline & & & & \\
\hline & & & & \\
\hline
\end{tabular}

Table (5): Mortality rate among the studied group:

\begin{tabular}{|c|c|c|}
\hline \multirow{2}{*}{ Variable } & \multicolumn{3}{|c|}{$(\boldsymbol{n = 2 1 2})$} \\
\cline { 2 - 3 } & No & $\%$ \\
\hline Mortality: & & \\
No & 210 & 99.1 \\
Yes & 2 & 0.9 \\
\hline \multirow{2}{*}{ Variable } & \multicolumn{2}{|c|}{$(\boldsymbol{n}=\mathbf{2 1 2})$} \\
\cline { 2 - 3 } No & $\%$ \\
\hline Causes of Mortality: & & \\
Primary hemorrhage & 1 & 0.5 \\
Pulmonary embolism & 1 & 0.5 \\
\hline
\end{tabular}

Table (6): Relation between complication and different data of the studied group: 


\begin{tabular}{|c|c|c|c|c|c|c|}
\hline \multirow[t]{2}{*}{ Variable } & \multicolumn{2}{|c|}{$\begin{array}{c}\text { Complicated } \\
(n=24)\end{array}$} & \multicolumn{2}{|c|}{$\begin{array}{c}\text { Not Complicated } \\
(n=188)\end{array}$} & \multirow{2}{*}{$x^{2}$} & \multirow[t]{2}{*}{$\mathbf{P}$} \\
\hline & No & $\%$ & No & $\%$ & & \\
\hline $\begin{array}{l}\text { Age group: } \\
<45 \text { years } \\
\geq 45 \text { years }\end{array}$ & $\begin{array}{c}5 \\
19\end{array}$ & $\begin{array}{l}20.8 \\
79.2\end{array}$ & $\begin{array}{l}89 \\
99\end{array}$ & $\begin{array}{l}47.3 \\
52.7\end{array}$ & 6.06 & $0.01 *$ \\
\hline $\begin{array}{c}\text { Parity: } \\
\text { Virgin } \\
\text { No } \\
\text { Para one } \\
\text { Multipara }\end{array}$ & $\begin{array}{l}0 \\
0 \\
4 \\
20\end{array}$ & $\begin{array}{c}0 \\
0 \\
16.7 \\
83.3\end{array}$ & $\begin{array}{c}7 \\
22 \\
5 \\
154\end{array}$ & $\begin{array}{c}3.7 \\
11.7 \\
2.7 \\
81.9\end{array}$ & 13.54 & $0.004 * *$ \\
\hline $\begin{array}{c}\text { Type of surgery: } \\
\text { Simple hysterectomy } \\
\text { Wertheim operation } \\
\text { Adnexectomy } \\
\text { Classical repair } \\
\text { Myomectomy } \\
\text { Vaginal hysterectomy } \\
\text { Ovarian drilling } \\
\text { Repair of old perennial tear } \\
\text { Hymenotomy } \\
\text { Vault prolapse } \\
\text { TOT }\end{array}$ & $\begin{array}{l}12 \\
10 \\
0 \\
0 \\
2 \\
0 \\
0 \\
0 \\
0 \\
0 \\
0\end{array}$ & $\begin{array}{c}50 \\
41.7 \\
0 \\
0 \\
8.3 \\
0 \\
0 \\
0 \\
0 \\
0 \\
0\end{array}$ & $\begin{array}{l}82 \\
13 \\
23 \\
21 \\
17 \\
12 \\
11 \\
3 \\
2 \\
2 \\
2\end{array}$ & $\begin{array}{c}43.6 \\
6.9 \\
12.2 \\
11.2 \\
9 \\
6.4 \\
5.9 \\
1.6 \\
1.1 \\
1.1 \\
1.1\end{array}$ & 33.60 & $<0.001 * *$ \\
\hline $\begin{array}{c}\text { Doctor: } \\
\text { Assistant lecture } \\
\text { Lecture } \\
\text { Assistant Prof or Prof }\end{array}$ & $\begin{array}{c}2 \\
8 \\
14\end{array}$ & $\begin{array}{c}8.3 \\
33.3 \\
58.3\end{array}$ & $\begin{array}{c}25 \\
48 \\
115\end{array}$ & $\begin{array}{l}13.3 \\
25.5 \\
61.2\end{array}$ & 0.93 & $\begin{array}{c}0.63 \\
\text { NS }\end{array}$ \\
\hline
\end{tabular}

Table (7): Relation between complication and previous laparotomy of the studied group:

\begin{tabular}{|c|c|c|c|c|c|c|}
\hline \multirow{2}{*}{ Variable } & \multicolumn{2}{|c|}{$\begin{array}{c}\text { previous laparotomy } \\
\text { (n=118) }\end{array}$} & $\begin{array}{c}\text { No previous abdominal } \\
\text { surgery } \\
\text { (n=94) }\end{array}$ & \multirow{2}{*}{$\mathbf{x}^{\mathbf{2}}$} & P \\
\cline { 2 - 5 } & No & \% & No & \% & & \\
\hline Complicated & 19 & 16.1 & 5 & 5.3 & \multirow{2}{*}{6.06} & $0.01 *$ \\
\hline $\begin{array}{c}\text { Not } \\
\text { complicated }\end{array}$ & 99 & 83.9 & 89 & 94.7 & & \\
\hline
\end{tabular}


Table (8): Relation between complication and body mass index (BMI) of the studied group:

\begin{tabular}{|c|c|c|c|c|c|c|}
\hline \multirow[t]{2}{*}{ Variable } & \multicolumn{2}{|c|}{$\begin{array}{c}\text { BMI } \\
(25-30) \mathrm{Kg} / \mathrm{M}^{2} \\
(n=137)\end{array}$} & \multicolumn{2}{|c|}{$\begin{array}{c}\text { BMI } \\
>30 \mathrm{Kg} / \mathrm{M}^{2} \\
(\mathrm{n}=75)\end{array}$} & \multirow[t]{2}{*}{$x^{2}$} & \multirow[t]{2}{*}{$\bar{P}$} \\
\hline & No & $\%$ & No & $\%$ & & \\
\hline $\begin{array}{c}\text { Septic wound infection } \\
\text { Present } \\
\text { Absent }\end{array}$ & $\begin{array}{c}2 \\
135\end{array}$ & $\begin{array}{c}1.4 \\
98.6\end{array}$ & $\begin{array}{c}3 \\
72\end{array}$ & $\begin{array}{c}4.0 \\
96.0\end{array}$ & 1.35 & 0.22 \\
\hline $\begin{array}{l}\text { Bladder injury } \\
\text { Present } \\
\text { Absent }\end{array}$ & $\begin{array}{c}4 \\
133\end{array}$ & $\begin{array}{c}2.9 \\
97.1\end{array}$ & $\begin{array}{c}1 \\
74\end{array}$ & $\begin{array}{c}1.3 \\
98.7\end{array}$ & 0.53 & 0.46 \\
\hline $\begin{array}{c}\text { Respiratory tract infection } \\
\text { Present } \\
\text { Absent }\end{array}$ & $\begin{array}{c}1 \\
136\end{array}$ & $\begin{array}{c}0.7 \\
99.3\end{array}$ & $\begin{array}{c}3 \\
72\end{array}$ & $\begin{array}{c}4.0 \\
96.0\end{array}$ & 2.8 & 0.09 \\
\hline $\begin{array}{c}\text { Venous Thromboembolism (VTE) } \\
\text { Present } \\
\text { Absent }\end{array}$ & $\begin{array}{c}0 \\
137\end{array}$ & $\begin{array}{c}0.0 \\
100.0\end{array}$ & $\begin{array}{c}4 \\
71\end{array}$ & $\begin{array}{c}5.3 \\
94.7\end{array}$ & 7.44 & $0.006 *$ \\
\hline $\begin{array}{c}\text { GIT injury } \\
\text { Present } \\
\text { Absent }\end{array}$ & $\begin{array}{c}2 \\
135\end{array}$ & $\begin{array}{c}1.4 \\
98.6\end{array}$ & $\begin{array}{c}1 \\
74\end{array}$ & $\begin{array}{c}1.3 \\
98.7\end{array}$ & 0.005 & 0.94 \\
\hline $\begin{array}{c}\text { Primary hemorrhage in OR } \\
\text { Present } \\
\text { Absent }\end{array}$ & $\begin{array}{c}1 \\
136\end{array}$ & $\begin{array}{c}0.7 \\
99.3\end{array}$ & $\begin{array}{c}1 \\
74\end{array}$ & $\begin{array}{c}1.3 \\
98.7\end{array}$ & 1.9 & 0.66 \\
\hline $\begin{array}{l}\text { Pulmonary edema } \\
\text { Present } \\
\text { Absent }\end{array}$ & $\begin{array}{c}1 \\
136\end{array}$ & $\begin{array}{c}0.7 \\
99.3\end{array}$ & $\begin{array}{c}0 \\
75\end{array}$ & $\begin{array}{c}0.0 \\
100.0\end{array}$ & 0.55 & 0.45 \\
\hline
\end{tabular}

